\title{
Comparative Pathology of Neurovirulent Lineage I (NY99/385) and Lineage 2 (SPU93/0I) West Nile Virus Infections in BALBc Mice
}

\author{
J. H. Williams ${ }^{1,2}$, J. D. L. Mentoor ${ }^{2}$, E. Van Wilpe ${ }^{3}$, and M. Venter ${ }^{2,4}$
}

\author{
Corresponding Author: \\ J. H. Williams, Section of Pathology, Department of Paraclinical Sciences, Faculty of Veterinary Science, University of Pretoria, Onderstepoort, 0110 \\ Republic of South Africa. \\ Email: june.williams@up.ac.za
}

\begin{abstract}
The pathology in mice infected with neurovirulent South African lineage 2 West Nile virus (WNV) strains has not previously been described. Three- to 4-month-old male BALBc mice were infected with South African neurovirulent lineage 2 (SPU93/0I) or lineage I (NY385/99) WNV strains and the gross and microscopic central nervous system (CNS) and extra-CNS pathology of both investigated and compared. Mice infected with both lineages showed similar illness, paralysis, and death from days 7 to II postinfection (PI). Two survivors of each lineage were euthanized on day 2I PI. WNV infection was confirmed by nested real-time reverse transcription polymerase chain reaction of tissues, mostly brain, in the majority of mice euthanized sick or that died and in I healthy lineage 2 survivor. Gross lesions caused by both lineages were identical and included marked gastric and proximal small intestinal fluid distension as described in a previous mouse study, but intestinal microscopic lesions differed. CNS lesions were subtle. Immunohistochemical (IHC)-positive labeling for WNV E protein was found in neurons multifocally in the brain of 3 lineage I-infected and 3 lineage 2-infected mice from days 9 to II PI, 4 of these including brainstem neurons, and of cecal myenteric ganglion neurons in I lineage 2-infected day $8 \mathrm{PI}$ mouse. Findings supported hypotheses in hamsters that gastrointestinal lesions are likely of brainstem origin. Ultrastructurally, virus-associated cytoplasmic vesicular or crystalline structures, or amorphous structures, were found to label IHC positive in control-positive avian cardiomyocytes and mouse thalamic neurons, respectively, and WNV-like 50-nm particles, which were scarce, did not label.
\end{abstract}

\section{Keywords}

BALBc mice, histopathology, immunohistochemistry, neurovirulent, pathology, ultrastructure, West Nile virus lineages I and 2

West Nile virus (WNV) is a widespread, single-stranded, positive-sense RNA virus of the genus Flavivirus, family Flaviviridae. WNV strains primarily fall into 2 lineages, 1 and 2 , with neurovirulent lineage 1 strains mainly found in the Northern Hemisphere ${ }^{18,25,33}$ and lineage 2 being endemic to Southern Africa and Madagascar. ${ }^{8}$ Neurovirulent lineage 2 strains have caused severe and fatal disease in horses ${ }^{8,43}$ and humans ${ }^{8,53}$ in South Africa and, since 2004, in Europe in birds, ${ }^{3,13,35}$ horses, ${ }^{23}$ and humans. ${ }^{11,30,31,34,37}$ In 2010, a single fatal equine case was identified as lineage 1 in South Africa. ${ }^{42}$

The original $1937 \mathrm{WNV}$ isolate from a febrile woman in Uganda was of lineage $2^{18}$ and neurovirulent in mice, causing illness and death from 6 to 8 days postinoculation and with viral-induced lesions essentially limited to the central nervous system (CNS). ${ }^{38}$ Different lines of experimental mice have since been infected with WNV of various lineages and strains, with detailed descriptions having been recorded mainly of CNS lesions. * Extra-CNS lesions during the same experiments were not recorded or were absent, ${ }^{12,36,49,50}$ scant, $^{28,38}$ or varied. ${ }^{14,21,29}$ Kimura et $\mathrm{al}^{21}$ in 2010, using 6-week-old $\mathrm{C} 3 \mathrm{H}$ mice infected with a lineage 1 (NY99-6922) strain, reported for the first time in mice distinctive macroscopic gastric and upper small intestinal dilation and filling with watery green content from day 7 postinfection (PI). Microscopically there were shortened villi and degeneration, necrosis, and immunohistochemical positivity,

\footnotetext{
'Department of Paraclinical Sciences, Faculty of Veterinary Science, University of Pretoria, Onderstepoort, Republic of South Africa

${ }^{2}$ Department of Medical Virology, Faculty of Health Sciences, University of Pretoria, Republic of South Africa

${ }^{3}$ Electron Microscopy Unit, Department of Anatomy, Faculty of Veterinary Science, University of Pretoria, Republic of South Africa

${ }^{4}$ Center for Respiratory Diseases and Meningitis, National Institute for Communicable Diseases, Sandringham, Johannesburg, Republic of South Africa
} 
especially of upper small intestinal myenteric ganglia but also of ganglia of other areas. Odelola and Oduye ${ }^{29}$ in 1977 reported no significant histological lesions in the small intestine of adult Swiss albino mice infected with a Nigerian WNV strain; they did, however report numerous foci of degenerated to necrotic hepatocytes. Brown et al ${ }^{7}$ in 2007 cited duodenum and pancreas as novel sites of $\mathrm{WNV}$ replication in $\mathrm{C} 3 \mathrm{H}$ and $\mathrm{C} 57 \mathrm{BL} / 6$ mice after footpad WNV inoculation but did not mention lesions.

Thymic atrophy and thymic and splenic lymphoid depletion due to lymphocyte necrosis were also recorded in sick $\mathrm{C} 3 \mathrm{H}$ mice as well as in 8 -week-old female $\mathrm{C} 57 / \mathrm{BL} / 6$ mice subcutaneously footpad inoculated with 1000 and 100 plaque-forming units of lineage $1 \mathrm{WNV}$ US strains in the WNV pathogenesis experiments of Kimura et al $(2010)^{21}$ and Garcia-Tapia et al (2007) ${ }^{14}$ respectively. Kimura et al commented that pathological events occurring in peripheral tissues during WNV infection of mice have been incompletely characterized.

The pathology in mice caused by a neurovirulent South African field strain of lineage $2 \mathrm{WNV}$ has not been reported previously or been compared with that caused by a known neurovirulent lineage $1 \mathrm{WNV}$ strain, and WNV-associated extra-CNS lesions in mice have been investigated only partially. The present study describes, illustrates, and compares gross and microscopic CNS and extra-CNS pathology in male 3- to 4-month-old BALBc mice after intraperitoneal infection with either neurovirulent New York lineage $1 \mathrm{WNV}$ strain NY385/99 or the South African neurovirulent lineage 2 WNV strain SPU93/01. The presence of both strains was tested for by nested real-time reverse transcription polymerase chain reaction (RT-PCR) and immunohistochemistry (IHC). Electron microscopy was done of the control positive lineage $1 \mathrm{WNV}$ infected avian tissue sourced from Canada and brain of one of the RT-PCR and IHC lineage 2-positive mice (case No. 18) in an attempt to demonstrate the presence of WNV in the IHC-positive areas of cell cytoplasm.

\section{Materials and Methods}

\section{Case and Virus Source}

Specific pathogen-free (SPF) WNV-infected mice and noninfected control mice mock-infected with phosphate-buffered saline (PBS), all of which had been previously mockvaccinated with PBS, were sourced from 2 registered, WNV vaccination and infection/challenge experiments performed in biosafety level 3 facilities at Deltamune (Pty.) Ltd. (Roodeplaat, Gauteng, South Africa [SA]) and the National Institute of Communicable Diseases (NICD) (Sandringham, Johannesburg, Gauteng, SA), respectively, after approval of the protocols by both the National Health Laboratory Services (NHLS) Animal Ethics and the University of Pretoria Animal Use and Care Committees (project number H019-10). In the experiment in which challenge was with both lineages 1 and $2 \mathrm{WNV}$, there were 10 mice per group. One each of the mock-vaccinated infected groups was sacrificed on day 0 of infection for blood studies and 1 each died unexpectedly on day $1 \mathrm{PI}$ of unrelated causes, leaving 8 per group for this pathology study ${ }^{44}$ From the other experiment conducted under identical circumstances, 5 mock-vaccinated lineage 2 -infected mice were sourced for the current study. The lineage $2 \mathrm{WNV}$ strain, SPU93/01, was isolated in 2001 from a 21-year-old South African woman hospitalized with meningo-encephalitis, who recovered, ${ }^{8}$ and was later reported as a neuroinvasive accidental laboratory infection in a 29 -year-old woman. ${ }^{41}$ It was obtained from Professor Janusz Paweska, Centre for Emerging Diseases and Zoonoses, NICD. The lineage 1 infection strain, NY385/99, was isolated from a bird that died in 1999 in New York and obtained from the late Dr R. E. Shope and Dr D. W. C. Beasley of the University of Texas Medical Branch, Galveston. Both strains were known to be highly neuroinvasive. ${ }^{6,41,45}$

\section{Infection of Mice}

Healthy PBS mock-vaccinated susceptible male BALBc mice 3 to 4 months of age were infected on day 0 of a 21-day vaccine-challenge/infection trial with WNV lineage 2 strain, SPU93 $/ 01^{8}(n=13$ : case Nos. $6-9,11-13,16-19,23$, and $24)$, or the lineage 1 strain, NY385/99 ( $n=8$ : case Nos. 10, $14,15,20-22,25$, and 26) (Table 1). ${ }^{44}$ As noninfected controls, 1 healthy mouse was euthanized on day 0 of the vaccine trial, 49 days prior to day 0 of infection/challenge (case No. 1), and 4 PBS mock-vaccinated, mock-infected healthy mice were euthanized either on day 0 of the infection/challenge trial (case Nos. 2 and 3), day 7 (case No. 4), or day 21 PI (case No. 5) (Table 1). Two lineage 2 -infected mice were euthanized on day 5 PI prior to showing clinical signs, and 2 each with lineage 1 and 2 infections were euthanized on day 21 PI after showing clinical recovery (case Nos. 23-26) (Table 1). All other WNV-infected mice died (case Nos. 9, 11, 12, 14-18, and 20-22) or were euthanized while sick (case Nos. 8, 10, and 19) (Table 1).

The viruses were titrated in Vero cells to determine the dilution to be used. A dose of $1 \times 10^{4} \mathrm{TCID}_{50} \mathrm{U} / \mathrm{ml}$ of both strains, shown in previous mouse studies to be $100 \%$ fatal, ${ }^{4,45}$ was used for intraperitoneal inoculation to ensure successful infection of all mice for the vaccine studies. ${ }^{4}$

Mice were observed for signs of disease for 21 days following infection. They were evaluated as paralyzed when they remained stationary with variable intermittent body tremors, rocking, or inability to move their limbs on stimulation or on being lifted from the cage. ${ }^{36}$ Mice seen unable to move or too disorientated to reach food or water were euthanized.

Euthanasia was either by intraperitoneal injection of sodium pentobarbitone, $200 \mathrm{mg} / \mathrm{ml}$ (Euthanaze; Bayer Animal Health [AH], Isando, SA), or by intramuscular xylazine hydrochloride, $20 \mathrm{mg} / \mathrm{ml}$ (Rompun 2\%; Bayer AH), at $5 \mathrm{mg} / \mathrm{kg}$ body mass combined with ketamine hydrochloride, $100 \mathrm{mg} / \mathrm{ml}$ (Anaket$\mathrm{V}$; Bayer $\mathrm{AH}$ ), at $35 \mathrm{mg} / \mathrm{kg}$ body mass, with exsanguination from the heart as soon as deep anesthesia had occurred. Two surviving mice from each lineage infection group were euthanized on day 21 PI by carbon dioxide inhalation. 
Table I. Results of Real-Time RT-PCR, IHC, Gross and Microscopic Pathology in Control Noninfected and WNV Lineage I (NY99/385)-Infected and 2 (SPU93/0I)-Infected 3- to 4-Month-Old Male BALBc Mice.

\begin{tabular}{|c|c|c|c|c|c|c|c|c|c|c|c|c|}
\hline \multirow[b]{2}{*}{ Day PI } & \multirow[b]{2}{*}{$\begin{array}{l}\text { Case } \\
\text { No. }\end{array}$} & \multirow[b]{2}{*}{$\begin{array}{l}\text { WNV lin I } \\
\text { or lin2 }\end{array}$} & \multirow[b]{2}{*}{$\begin{array}{l}\text { Euthanized, } \\
\text { Sick, Died }\end{array}$} & \multirow[b]{2}{*}{$\begin{array}{l}\text { Real-Time RT- } \\
\text { PCR WNV }\end{array}$} & \multirow[b]{2}{*}{$\begin{array}{l}\text { IHC on All } \\
\text { Tissues }\end{array}$} & \multirow[b]{2}{*}{ Grross PM } & \multicolumn{6}{|c|}{ Microscopic Lesions } \\
\hline & & & & & & & SI & $\mathrm{LI}$ & Spleen & $\begin{array}{l}\text { Lymph } \\
\text { Nodes }\end{array}$ & CNS & Other \\
\hline $\begin{array}{r}\text { Day } \\
0 \\
0 \\
7 \\
21\end{array}$ & $\begin{array}{l}I^{* \wedge} \\
2, * 3 * \\
4^{*} \\
5^{*}\end{array}$ & $\mathrm{NI}$ & $\begin{array}{l}\text { Not sick } \\
\text { E } \\
\text { E } \\
\text { E } \\
\text { E }\end{array}$ & $\begin{array}{l}1-5 \\
\text { neg }\end{array}$ & $\begin{array}{l}\mathrm{I}-5 \\
\text { neg }\end{array}$ & - & $\begin{array}{l}\text { Villi stunted } \\
\quad(4)\end{array}$ & - & $\begin{array}{l}\text { neg; } \\
\text { NE (3) }\end{array}$ & $\begin{array}{l}\text { Hyperplasia } \\
\text { (I) } \\
\text { NE (3) }\end{array}$ & $\begin{array}{c}\text { +PVhem } \\
\text { (I) }\end{array}$ & Hepatosis ( 3 and 5 ) \\
\hline \multirow[t]{2}{*}{ Day 5} & 6 & $\operatorname{lin} 2$ & E not sick & neg & neg & - & + & + & + & NE & + & - \\
\hline & 7 & $\operatorname{lin} 2$ & E not sick & neg & neg & - & - & + & +- & $\mathrm{NE}$ & - & High protein lung edema, hepatosis \\
\hline \multirow[t]{2}{*}{ Day 7} & 8 & $\operatorname{lin} 2$ & E sick & + & neg & st SI dist & +++ & + & $\begin{array}{l}+++ \text { necr } \\
\text { Icts DMs } \\
\text { marginal }\end{array}$ & $\begin{array}{l}++ \text { lct } \\
\text { necrosis }\end{array}$ & + & Interstitial pneumonia \\
\hline & $\begin{array}{r}9 \\
10\end{array}$ & $\begin{array}{l}\operatorname{lin} 2 \\
\operatorname{lin} 1\end{array}$ & $\begin{array}{l}\text { D } \\
\text { E sick }\end{array}$ & $\begin{array}{l}+ \\
+\end{array}$ & $\begin{array}{l}\text { neg } \\
\text { +neur deep brainstem }\end{array}$ & $\begin{array}{l}\text { st SI dist } \\
\text { st SI dist }\end{array}$ & $\begin{array}{l}+++ \\
+++\end{array}$ & $\begin{array}{l}+ \\
-\end{array}$ & $\begin{array}{l}+++ \\
+++\end{array}$ & $\begin{array}{l}++ \text { lct depl } \\
++\end{array}$ & $\begin{array}{l}+ \\
+\end{array}$ & $\begin{array}{l}\text { Ethmoid lct necrosis } \\
\text { Hepatosis }\end{array}$ \\
\hline \multirow[t]{4}{*}{ Day 8} & 11 & $\operatorname{lin} 2$ & $\mathrm{D}$ & + & + Cecal myenteric ganglion & st SI dist & +++ & Mucus & $\begin{array}{l}++ \text { Marginal } \\
\text { Ict depl }\end{array}$ & $\begin{array}{c}++\mathrm{SH} \text { lct } \\
\text { depl }\end{array}$ & + & Lipid hepatosis \\
\hline & 12 & $\operatorname{lin} 2$ & $\mathrm{D}$ & + & neg & st SI dist & + aut & - & NE & $\begin{array}{c}+++ \text { lct } \\
\text { depl }\end{array}$ & aut & Lipid hepatosis \\
\hline & 13 & $\operatorname{lin} 2$ & E sick & + & neg & st SI dist & $\begin{array}{l}+++ \text { Villus } \\
\text { fusion }\end{array}$ & + & $\begin{array}{r}+++ \text { Marginal } \\
\text { Ict necrosis }\end{array}$ & $\begin{array}{l}++ \text { lct } \\
\text { necrosis }\end{array}$ & + & $\begin{array}{l}\text { Pleuritis, diaphragm vasculitis, } \\
\text { peritonitis, interst pneum, } \\
\text { hepatosis }\end{array}$ \\
\hline & $\begin{array}{l}14 \\
15\end{array}$ & $\begin{array}{l}\operatorname{lin} 1 \\
\operatorname{lin} 1\end{array}$ & $\begin{array}{l}\mathrm{D} \\
\mathrm{D}\end{array}$ & $\begin{array}{l}\text { neg } \\
\text { neg }\end{array}$ & $\begin{array}{l}\text { neg } \\
\text { neg }\end{array}$ & $\begin{array}{l}\text { st SI dist } \\
\text { st, SI dist }\end{array}$ & $\begin{array}{l}+++ \text { neuts } \\
+++\end{array}$ & $\begin{array}{c}\text { mucus } \\
-\end{array}$ & $\begin{array}{l}+++ \\
++ \text { lct depl }\end{array}$ & $\begin{array}{l}++ \text { depl SH } \\
++ \text { depl SH }\end{array}$ & $\begin{array}{l}+ \\
+\end{array}$ & $\begin{array}{l}\text { Hepatosis } \\
\text { Lipid hepatosis }\end{array}$ \\
\hline \multirow[t]{2}{*}{ Day 9} & $\begin{array}{l}16 \\
17 \\
18 \\
19\end{array}$ & $\begin{array}{l}\operatorname{lin} 2 \\
\operatorname{lin} 2 \\
\operatorname{lin} 2 \\
\operatorname{lin} 2\end{array}$ & $\begin{array}{l}\text { D } \\
D \\
D \\
\text { E sick }\end{array}$ & $\begin{array}{c}+ \\
\text { neg } \\
+ \\
+\end{array}$ & $\begin{array}{l}++ \text { Cortex } \\
\text { neg } \\
+ \text { Cortex, thalamus } \\
\text { +Cortex, brainstem }\end{array}$ & $\begin{array}{l}\text { st SI dist, melena } \\
\text { st SI dist } \\
\text { st SI dist, melena } \\
\text { st SI dist, } \\
\text { yellow-brown }\end{array}$ & $\begin{array}{l}+++ \\
+++ \\
+++ \\
+++\end{array}$ & $\begin{array}{c}- \\
+ \\
+ \\
\text { mucus }\end{array}$ & $\begin{array}{l}\text { ++lct depl } \\
+ \text { lct depl } \\
+ \\
+ \text { lct } \\
\quad \text { depl }\end{array}$ & $\begin{array}{l}++ \text { lct depl } \\
+ \text { SH } \\
+ \text { lct depl } \\
++ \text { lct depl } \\
\quad \text { SH }\end{array}$ & $\begin{array}{l}+ \\
+ \\
+ \\
+\end{array}$ & $\begin{array}{l}\text { Lipid hepatosis } \\
\text { Hepatosis } \\
\text { Lipid hepatosis } \\
\text { - }\end{array}$ \\
\hline & $\begin{array}{l}20 \\
21\end{array}$ & $\begin{array}{l}\operatorname{lin} 1 \\
\operatorname{lin} 1\end{array}$ & $\begin{array}{l}\mathrm{D} \\
\mathrm{D}\end{array}$ & $\begin{array}{l}+ \\
+\end{array}$ & $\begin{array}{l}\text { +Brainstem } \\
\text { neg }\end{array}$ & $\begin{array}{l}\text { st SI dist, melena } \\
\text { st SI dist }\end{array}$ & $\begin{array}{l}+++ \\
+++\end{array}$ & $\begin{array}{c}\text { neuts } \\
-\end{array}$ & $\stackrel{+}{\mathrm{N} E}$ & $\begin{array}{l}+ \\
+\end{array}$ & $\begin{array}{l}+ \\
+\end{array}$ & $\begin{array}{l}\text { Hepatosis, purulent mesenteritis } \\
\text { Hepatosis }\end{array}$ \\
\hline Day II & 22 & $\operatorname{lin} I$ & $\begin{array}{l}\text { Sick } 2 \text { days } \\
\text { D }\end{array}$ & + & $\begin{array}{l}\text { +Cerebellar peduncle, } \\
\text { cortex, deep brainstem }\end{array}$ & $\begin{array}{l}\text { st SI dist, melena, } \\
\text { meningeal } \\
\text { hem }\end{array}$ & +++ & Mucus & +++ & NE & + & $\begin{array}{l}\text { FB pleuritis, mesenteric vasculitis, lipid } \\
\text { hepatosis }\end{array}$ \\
\hline \multirow[t]{2}{*}{ Day 21} & $\begin{array}{l}23 \\
24 \\
25\end{array}$ & $\begin{array}{l}\operatorname{lin} 2 \\
\operatorname{lin} 2 \\
\operatorname{lin} 1\end{array}$ & $\begin{array}{l}E \\
E \\
E\end{array}$ & $\begin{array}{c}+ \\
\text { neg } \\
\text { neg }\end{array}$ & $\begin{array}{l}\text { neg } \\
\text { neg } \\
\text { neg }\end{array}$ & $\begin{array}{c}\text { Splenomegaly } \\
- \\
-\end{array}$ & $\begin{array}{l}\text { neuts } \\
\text { Villi stunted } \\
\text { neuts }\end{array}$ & $\begin{array}{l}- \\
- \\
-\end{array}$ & $\begin{array}{l}- \\
- \\
-\end{array}$ & $\begin{array}{l}\text { NE } \\
- \\
-\end{array}$ & $\begin{array}{l}+ \\
\text { PVhem } \\
\text { Focal } \\
\text { neur } \\
\text { calc }\end{array}$ & $\begin{array}{l}\text { Hepatosis } \\
\text { Hepatosis } \\
\text { Hepatosis, distended bladder }\end{array}$ \\
\hline & 26 & $\operatorname{lin} I$ & $\mathrm{E}$ & neg & neg & - & neuts & - & - & - & PVhem & Hepatosis \\
\hline
\end{tabular}

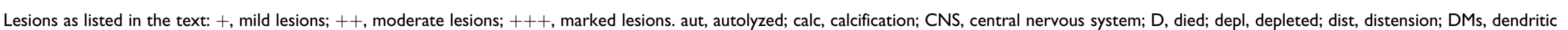

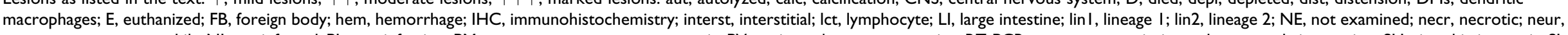

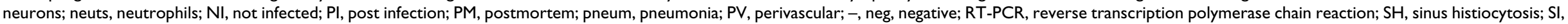
small intestine; st, stomach; WNV, West Nile virus; *, control, noninfected mice from infection trial; ${ }^{\wedge}$, control mouse from day 0 of vaccine trial. 
Digital images were taken with Panasonic Lumix FZ10 and FZ45 cameras (Panasonic Corporation, Ariake Tokyo, Japan). Images of histological lesions of all cases were taken using an Olympus BC50 microscope (Olympus, Hamburg, Germany) with associated $\mathrm{CC} 12$ soft imaging system and analySIS software (Olympus).

\section{Necropsies and Collection of Tissue Specimens}

After blood and aseptic fresh tissue collection from euthanized mice and aseptic tissue collection from mice that died, the abdominal and thoracic cavities were opened ventrally and left laterally after reflection of the diaphragm, to allow the $10 \%$ neutral buffered formaldehyde to penetrate. The dorsal cranium was removed and the skin along the dorsum of the neck and trunk opened and dissected away from the subcutis and spine. After a minimum of 48 hours and in most cases at least 7 days, full necropsies were performed. Tissue slices of 1 to $2 \mathrm{~mm}$ width were cut from approximately 30 tissues from each mouse and placed in a single cassette for routine alcohol dehydration, wax embedding, 5- $\mu \mathrm{m}$-thick microtome sectioning, hematoxylin and eosin (HE) staining, and light microscopic examination.

Tissues sampled for histopathology included haired skin from trunk or left hind leg, left quadriceps muscle, bladder, liver, spleen, left and right kidneys, both lungs, serial horizontal sections of heart, serial vertical transverse sections of brain and cerebellum, tongue, ethmoid region, transsected lumbar or thoracic vertebrae incorporating vertebral body bone marrow and occasionally spinal cord, pyloric region of stomach, pancreas, duodenum, jejunum, ileum, cecum, descending colon, mesenteric lymph node, testis, mesenteric fat, footpads and digits of left hind foot, and occasionally adrenal gland, eye, esophagus, and dissected-out lumbar spinal cord. Regions of the brain examined included the olfactory lobe, cerebral cortex, hippocampus/thalamus, pons/medulla oblongata, and cerebellum. The thin thread-like spinal cord or bits thereof, and occasionally spinal nerves, in most cases of lumbar origin and either in trans- or longitudinal section, were examined in case Nos. 2 to $5,8,10$ to 13,16 to 19 , and 23 to 26 : in the remaining cases, it was likely situated in a deeper plane in the wax blocks or cut away during section preparation.

\section{Immunohistochemistry}

Immunohistochemical labeling of all tissues was performed using Thermo Scientific (Pierce Biotechnology, Rockford, IL) rabbit polyclonal WNV E antibody at dilution 1:50 according to the avidin-biotin complex technique. ${ }^{16}$ Trial labeling of known RT-PCR positive avian heart infected with lineage 1 WNV (Dr Josepha DeLay, University of Guelph, Ontario, Canada) as well as a known RT-PCR-positive mouse brain from this study (case No. 18, day 9 PI with WNV SPU93/01) was done to develop a suitable protocol. Mouse case No.1 sacrificed on day -49 was used as a negative control. The Novolink Polymer Detection System (Novocastra Laboratories
Ltd, Newcastle upon Tyne, UK) was used. Novored Substrate (Vector Laboratories, Burlingame, CA) was applied, after which differentiation was done by hand, with hematoxylin counterstaining and mounting in Entellan (Merck KGaA, Darmstadt, Germany) mounting medium. WNV-positive mouse brain and avian heart controls, the negative control mouse, and known positive rabies tissue sections were also labeled immunohistochemically with polyclonal rabies antibody (prepared by the late Dr Ken Charlton, Animal Diseases Research Institute, Ontario, Canada) at dilution 1:500 as irrelevant antibody.

\section{WNV RNA Detection}

Nested real-time RT-PCR (rRT-PCR) with WNV-specific primers was carried out on the fresh tissues of all cases. This was performed with a nested rRT-PCR amplification method as previously described. ${ }^{52}$

\section{Electron Microscopy}

IHC positively labeled cells from the Canadian avian lineage $1 \mathrm{WNV}$ control-positive heart as well as thalamic neurons of mouse case No. 15 were prepared for electron microscopy (EM) by the pop-off method for reembedding in resin. ${ }^{17}$ Briefly, the relevant areas on the light microscope slides are flooded with a xylene and epoxy resin mixture before inverting the slide onto a resin-filled preshaped polyethylene mold with a hinged lid (BEEM capsule; Agar Aids, Stansted, Essex, UK) for polymerization. This technique enables examination of specific cells identified by light microscopy, in this case avian cardiomyocytes and mouse neurons that were positively labeled by IHC, to investigate which structures were being labeled. Ultra-thin resin sections were contrasted with uranyl acetate and lead citrate and examined with a Philips CM10 (Philips Electron Optical Division, Eindhoven, The Netherlands) transmission electron microscope operated at $80 \mathrm{kV}$, and digital images were captured with a Megaview III sidemounted digital camera (Olympus Soft Imaging Solutions $\mathrm{GmbH}$, Münster, Germany) and iTEM software (Olympus Soft Imaging Solutions $\mathrm{GmbH}$ ) to adjust brightness and contrast.

\section{Results}

\section{Clinical Signs}

Clinical signs shown by both lineage 1 and $2 \mathrm{WNV}$-infected mice were similar and included depression, hunched body posture, ruffled fur, dehydration as tested by lifting a skin fold, body tremors or lateral rocking while stationary, circling, inability to drink or eat from the overhead water spout and food cage, very slow crawling movement when touched, paresis, paralysis, and abdominal distension.

Table 1 shows daily progress of illness, death, or euthanasia of mice infected with both lineages. Two mice from each infection group that had shown signs of illness but had recovered 
were euthanized on day 21 PI (Table 1). Ten mice were found dead after showing mild or no clinical signs during the twicedaily observations: time from onset of clinical signs to death was generally less than 12 hours except for case No. 22 (lineage 1), which was hunched and showed slow movement and rocking for 2 days prior to death. Mice started dying on day 7 in both lineage 1 and 2 groups.

\section{Gross Necropsy Findings}

All control mice, infected mice euthanized prior to manifestation of clinical signs (case Nos. 6 and 7 inoculated with lineage 2 ), and mice surviving infection with both lineages showed no significant gross lesions apart from visceral congestion and pulmonary hemorrhages (Table 1).

WNV-affected mice were generally dehydrated and had distended abdomens and ruffled fur. Small intestine and stomach were markedly fluid and sometimes gas distended, and serosae were congested (Table 1, Fig. 1). After formalin fixation when necropsies were continued, the stomachs deflated on removal, and the distended proximal small intestines were fragile and occasionally broke, releasing watery content. Comparative gastrointestinal distension in various mice is illustrated (Figs. 2-4). Gastrointestinal contents were variably green-gray fluid, watery to granular dark gray-brown, pasty brown-yellow, or dark red-brown to red-black granular fluid (Fig. 4, Table 1). Melenic contents were present in 3 mice dying at day 9 PI (case Nos. 16 and 18 with lineage 2 and case No. 20 with lineage 1 infection) and case No. 22, the lineage 1-infected day 11 PI mouse (Table 1).

In all fatalities or sick euthanized mice, the distal jejunum, ileum, cecum, and descending colon appeared atrophic with very little content; fecal pellets if present were generally few, dry, small, and firm. Control mice, lineage 2-infected case Nos. 6 and 7, and the 4 survivors (case Nos. 23 and 24 of lineage 2 and case Nos. 25 and 26 of lineage 1) had by contrast small stomachs filled with granular food content; narrow, relatively empty small intestines; cecae filled with pasty gray-green feces; and several large elongated fecal pellets in their colons.

Mice euthanized on day 5 PI (lineage 2-infected case Nos. 6 and 7) had ample abdominal fat and no intestinal distension, and their stomachs contained only a small amount of granular commercial food. Abdominal fat was generally mildly to markedly reduced in amount in clinically affected mice compared with that of healthy control mice, case Nos. 6 and 7, and surviving mice.

Meninges, brain, cerebellum, and lumbar spinal cord were congested, and case No. 22 (lineage 1) had visible meningeal hemorrhage. Lungs generally appeared consolidated due to pulmonary hemorrhage and congestion. Livers in some uninfected controls, sick mice, and the survivors were pale yellow-tan (Table 1) and slightly friable. One surviving mouse had mild splenomegaly (case No. 23, lineage 2), and bladder size varied, with some being empty and that of case No. 25 (lineage 1 survivor) moderately distended.

\section{Histopathology}

CNS lesions were present but scant and subtle in all mice showing neurological signs infected with both lineages 1 and 2 WNV. All affected mice showed moderate to marked diffuse meningeal, cerebral, cerebellar, and brainstem vascular congestion, and the most common lesion was small multifocal perivascular petechiae, seen randomly in meninges (case Nos. $6,8-10$, and 12-22), and in various affected mice in all parenchymal regions studied, including cortical gray and/or white matter, hippocampus/thalamus, occasionally medulla/pons, cerebellar white matter, and/or choroid plexus. Congestion and perivascular hemorrhages were less prominent in survivors and lineage 2-infected case No. 7 euthanized prior to clinical signs. Diffuse or regional mild gliosis was found in case No. 9 (lineage 2) of the cerebellar white matter and medulla/pons, case No. 20 (lineage 1) of the brainstem, and case Nos. 10 (lineage 1), 14 (lineage 1), 11 (lineage 2), and 13 (lineage 2) of the cortex. Single or very few lymphocytes and rare neutrophils were seen perivascularly, affecting very few vessels of meninges (case Nos. 6 and 16 [lineage 2] and 10, 13, 15, and 20 [lineage 1]), cortex (case Nos. 14 [lineage 1] and 23 [lineage 2 survivor]), hippocampus/thalamus (case Nos. 11, 16, 17, 20, and 22 [lineage 2] and 15 [lineage 1]), periventricularly (case Nos. 11, 20, and 21, lineage 1), medulla/pons (case Nos. 17 and 22, lineages 2 and 1), brainstem (case No. 14, lineage 1), and choroid plexus (case No. 11, lineage 2). Foci of cortical edema (case No. 22, lineage 1), occasional large neuron necrosis in the brainstem (case No. 13, lineage 2), and intermittent cerebellar Purkinje cell necrosis (case Nos. 13 and 19, lineage 2) were also seen. By comparison, in the 5 noninfected control mice, the only lesion found was occasional perivascular petechiae in the medulla/pons of case No. 1.

Lumbar or distal thoracic spinal cord of control case Nos. 2 to 5; lineage $2 \mathrm{WNV}$-affected case Nos. 9, 12, 13, 16 to 19, and survivor case No. 24; and lineage 1-infected case No. 10 and survivors case Nos. 25 and 26 showed no significant lesions. Gray matter gliosis was seen in case Nos. 8 (lineage 2 day 7 PI) and 11 (lineage 2 day 8 PI). No significant lesions were found in other neural tissues examined in both lineage 1- and 2-infected mice, including several spinal ganglia, mesenteric ganglia, spinal nerves, peripheral nerves of skin, foot and tongue, ethmoid/nasal epithelium, eyes, and optic nerves.

Case Nos. 6 and 7 (lineage 2) euthanized on day 5 PI prior to clinical signs had no macroscopic lesions, but case No. 6 had mild early intestinal histological lesions similar to those in mice showing macroscopic lesions from day 7 PI. These included scattered neutrophils in the small intestinal lamina propria, mild crypt single-cell necrosis with sloughing, some Paneth cell degranulation, mild serum exudation into intestinal glandular lumens, occasional splenic white pulp lymphocyte necrosis, and occasional perivascular round cell presence in the meninges.

The most striking histological lesions in the clinically affected WNV-infected mice of either lineage (case Nos. 8-22) occurred in the distended proximal small intestine and 


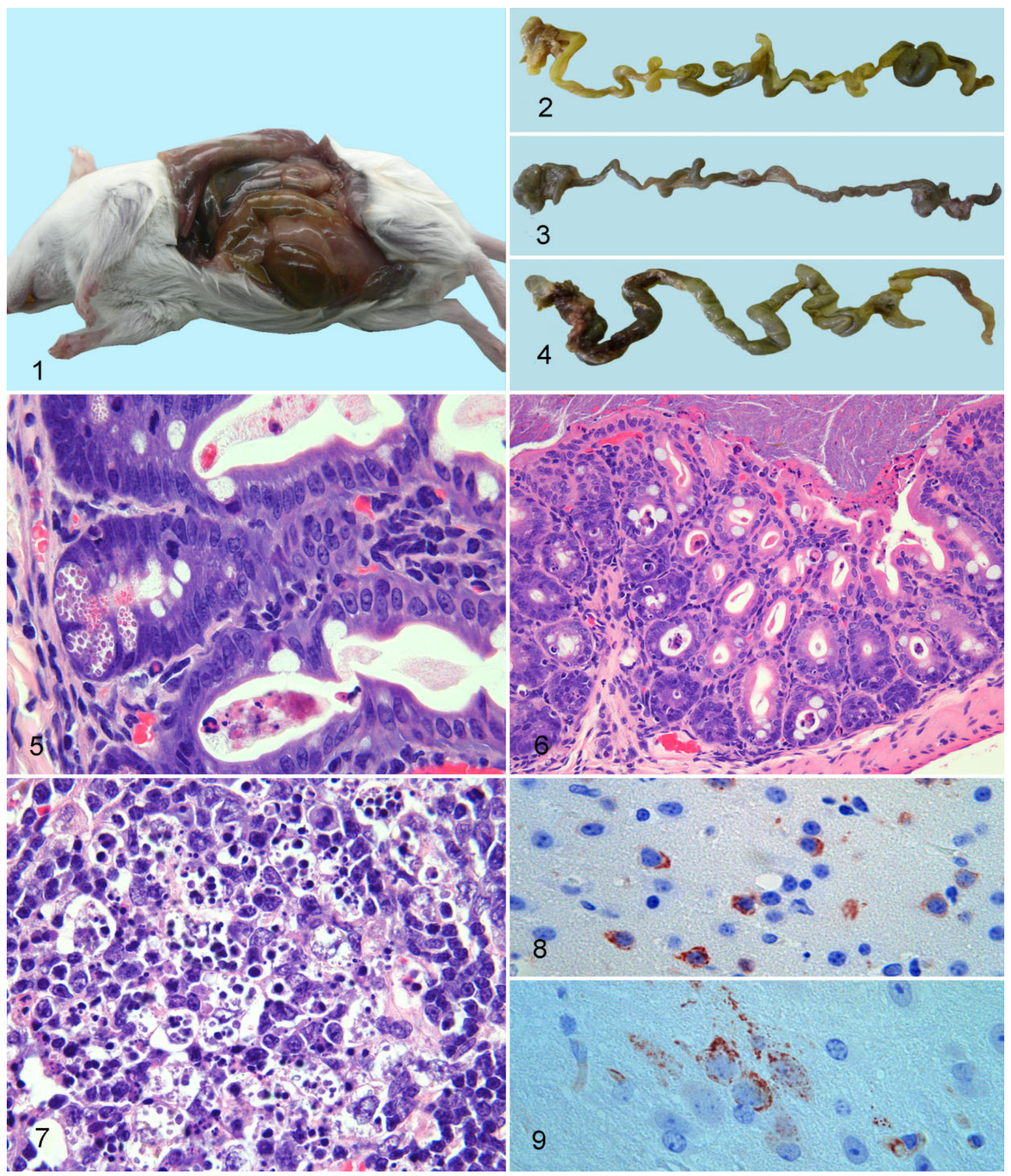

Figure I. Opened abdomen; case No. 10, lineage I West Nile virus (WNV), euthanized day 7 postinfection (PI). Marked visceral congestion, gastric and small intestinal distension. Figure 2. Gastrointestinal tract; case No. 4, euthanized day 7. Normal control; stomach to the left of image. Figure 3. Gastrointestinal tract; case No. 6, lineage 2 WNV, euthanized day 5 PI. Apparently normal; stomach on left of image. Figure 4. Gastrointestinal tract; case No. 18, lineage 2, died day 9 PI. Deflated stomach on left of image; marked proximal small intestinal distension with melenic contents; empty cecum and colon. Figure 5. Small intestine; case No. 8, lineage 2, euthanized day 7 PI. Crypt enterocyte necrosis and 
included those lesions seen in case No. 6 but were severe in comparison (Fig. 5). Also seen were mild to moderate lamina propria neutrophil influx, with some neutrophils, lymphocytes, and plasma cells undergoing necrosis; occasional villus tip hemorrhages; and variable sloughing of villus tip enterocytes along with necrotic leucocytes and serum exudation into the intestinal lumen. Villus fusion was found in 1 small intestinal segment of case No. 13 (lineage 2) and shortened villi in control case No. 4 and lineage 2 survivor case No. 24 (Table 1).

Excessive cecal luminal mucus, mild occasional colonic crypt and/or luminal mucosal cell necrosis with sloughing (Fig. 6), and occasional neutrophils in the colonic mucosa were also seen in clinically affected mice with both lineages (Table 1). Bacteria, generally mixed and in varying numbers, were present in the lumen of both small and large intestines of most cases.

Myenteric ganglia of control mice and case Nos. 6 and 7 (lineage 2 infected and euthanized on day 5 PI prior to clinical signs) were easily visualized as small clusters of normal neurons, but in the WNV-affected cases that died, marked intestinal distension resulted in ganglia being difficult to identify. In the large intestine of some of the mice showing mucosal lesions, some ganglia appeared more cellular than normal, with neutrophils occasionally identified. In 1 colon section of case No. 17 (lineage 2), neutrophilic vascular leucostasis and exocytosis into the muscle layers was found, and lymphatics draining necrotic cell debris and neutrophils made visualization of myenteric ganglia difficult. Neuronal vacuolation seen in some ganglia of some mice that had died was ascribed to autolysis. ${ }^{51}$

Phagocytosis of splenic follicular marginal zone lymphocytes by dendritic macrophages was prominent in all mice infected with both lineages 1 and 2, which succumbed or were euthanized on day 7 PI and continued on day 8 (Fig. 7), with follicular lymphocytes becoming progressively depleted from days 8 to 9 except in case Nos. 18 (lineage 2, day 9 PI) and 20 (lineage 1, day 9 PI) (Table 1). Splenic extramedullary hemopoiesis diminished in the red pulp of affected mice and hemosiderophages increased in number compared with the spleens of healthy control mice.

Scattered macrophage phagocytosis of lymphocytes, follicular lymphocyte depletion, or lymph node sinus histiocytosis was found in mesenteric lymph nodes and intestinal Peyer patches from days 7 to 9 PI with both lineages (Table 1).

In survivor case Nos. 23 (lineage 2), 25 (lineage 1), and 26 (lineage 1), neutrophils remained scattered in small intestinal villus tips. Splenic and lymph node follicles and splenic red pulp of all survivors had recovered to resemble those of normal control mice regarding lymphocyte density, extramedullary hemopoiesis, and scant hemosiderophages. CNS in these cases showed minimal lesions, including occasional cortical (case No. 24, lineage 2) or hippocampal/thalamic (case No. 26, lineage 1) perivascular petechiae, with occasional cortical perivascular lymphocytes in the only survivor with brain still rRT-PCR positive for lineage $2 \mathrm{WNV}$ (case No. 23). A deep thalamic small cluster of mineralizing neurons was found in lineage 1 survivor case No. 25 (Table 1).

Lesions found in individual mice included submucosal ethmoid lymphocyte necrosis (case No. 9, lineage 2); necrotic vasculitis, purulent peritonitis, and pleuritis affecting both surfaces of the diaphragm (case No. 13, lineage 2); and necropurulent to hemorrhagic mediastinitis, pleuritis, and peri- and epicarditis affecting the caudodorsal thoracic cavity, associated with mixed bacteria, foreign material, interstitial pneumonia, and bacterial colonies in the spleen in case No. 22 (lineage 1) (Table 1).

Many mice, including healthy controls and infected animals, had mild microscopic to macroscopically visible hepatosis (Table 1). Lung lesions in most mice included congestion, areas of atelectasis, hemorrhage, and diffuse mild to moderate vascular neutrophilic leucostasis, and case No. 7 also had high protein alveolar edema. Testicles from all mice were undergoing spermatogenesis. Vertebral body bone marrow of all mice in general showed a predominance of neutrophil granulopoiesis. Thymus was not examined, being too small to visualize macroscopically for intentional sectioning. Hyperkeratosis of lingual epithelium and esophagus occurred in most anorexic, paralyzed sick mice with variable degranulation of mast cells seen in the lingual submucosa.

\section{Immunohistochemistry}

IHC on all tissues of all mice identified WNV brain positivity in 6 mice on days 7, 9, and 11 PI: 3 of lineage 1 on days 7, 9, and 11 PI and 3 of lineage 2 on day 9 PI. Positivity was intracytoplasmic, granular, and intense (Figs. 8, 9) in few small or large single scattered neurons or neurons in locally extensive areas of cortical gray matter (case Nos. 18 and 19 of lineage 2 and case No. 22 of lineage 1) (Fig. 8), thalamus (case No. 18, lineage 2), cerebellar peduncle white matter (case No. 22), and/or deep brainstem (case Nos. 10, 20, and 22 [lineage 1] and case No. 19 [lineage 2]) (Fig. 9) (Table 1). Specific nuclei were not identifiable due to sections often being cut at angles and to the scattered nature of most of the single positively labeled neurons. In case No. 11 (day 8 PI, lineage 2) neurons in a single cecal myenteric ganglion were also IHC positive (Table 1). IHC-positive neurons showed neither light

Figure 5. (continued) sloughing, Paneth cell degranulation, and protein exudation. Hematoxylin and eosin (HE). Figure 6. Colon; case No. 8. Crypt and luminal enterocyte necrosis and sloughing. HE. Figure 7. Spleen; case No. 8. Follicular marginal zone dendritic macrophage phagocytosis of lymphocytes and lymphocyte necrosis. HE. Figure 8. Cerebral cortex; case No. 19, lineage 2, euthanized day 9 PI. WNV E protein present in scattered neurons as cytoplasmic granular staining without visible pathology. Immunoperoxidase with Novored as chromogen and hematoxylin counterstain. Figure 9. Deep brainstem; case No. 10. WNV E protein positive cytoplasmic staining of some neurons without visible lesions. Immunoperoxidase with Novored as chromogen and hematoxylin counterstain. 
microscopically visible pathology nor associated glial or inflammatory leukocyte infiltration. The negative control and rabies-positive sections showed no antigen on WNV-IHC staining, and none of the sections stained positively for rabies antigen except the positive rabies control.

\section{WNV RNA Detection}

Viral RNA could be detected in the brain of 12 of 15 mice that died or were euthanized sick and infected with both lineages 1 and $2 \mathrm{WNV}$, from days 7 to $11 \mathrm{PI}$ (Table 1). Tissues of infected case Nos. 6 and 7 (lineage 2) euthanized on day 5 PI prior to development of clinical signs as well as fatal lineage 1 case Nos. 14 and 15 (day $8 \mathrm{PI}$ ) and 17 (day 9 PI) were WNV rRT-PCR and IHC negative. Of the 4 surviving infected mice euthanized at day 21 , only 1 lineage 2 -infected mouse (case No. 23) was rRT-PCR positive in brain tissue (Table 1).

\section{Ultrastructure}

Distinct WNV particles were absent in the ultra-thin sections prepared from the IHC, RT-PCR-positive avian cardiac fibers, but roughly spherical, faintly paracrystalline or amorphous structures, sometimes associated with endoplasmic reticulum, were present (Fig. 10). Occasional vesiculation or vacuolation related to these structures was evident. Pleomorphic amorphous structures were seen adjacent to dilated endoplasmic reticulum and vesicles in the lineage $2 \mathrm{WNV}$ antigen-positive cytoplasmic areas of mouse thalamic neurons (case No. 18, lineage 2) (Fig. 11), with a cluster of 50-nm diameter WNV-like particles with central dense cores and some with pale envelopes found in an IHC nonstaining area (Fig. 12).

\section{Discussion}

Intraperitoneal infection of 3- to 4-month-old male BALBc mice with neurovirulent lineage 1 NY99/385 or South African lineage 2 SPU93/01 WNV strains led to similar neurological signs in all mice and death in most animals from days 7 to 11 PI, with 2 mice infected with each lineage surviving infection. Gross and microscopic pathology were indistinguishable between the lineages, and the study confirmed the pathogenicity and neurovirulence in mice of SPU93/01 isolated from a South African woman with naturally acquired WNV neurological disease. ${ }^{8}$

Intraperitoneal inoculation was chosen for the vaccine studies from which the mice for this pathology study were sourced to ensure that all mice developed WNV neurological disease, as previously described. ${ }^{4,45}$ For a strictly pathogenesis study, however, intradermal or subcutaneous inoculation to mimic natural infection by mosquito vectors would have been preferable. $^{14,20,21}$ The general lack of light microscopically visible lesions and IHC positivity in the spinal cord in mice of this study was likely due to direct hematogenous spread of virus from the peritoneal cavity and visceral lymphoid sites of replication to the brain. Brain entry by WNV in mice is commonly reported from blood via olfactory neuroepithelium and olfactory bulbs, ${ }^{7,49}$ by the cerebellar ${ }^{49}$ or choroid plexus ${ }^{20}$ vascular routes, or by retrograde neuronal transport via sympathetic or sensory nervous systems. ${ }^{20}$ Footpad inoculation, however, results in transneural spread into the ipsilateral spinal cord ventral horn via the sciatic nerve ${ }^{7}$ with resultant neuronal IHC positivity ${ }^{14,21}$ and/or histological changes, ${ }^{14}$ which were absent in the current study.

Mouse numbers were limited by ethics to the minimum needed for adequate statistical analysis for vaccine efficacy testing, which in the main study ${ }^{44}$ was 10 per group. As mentioned previously, numbers of nonvaccinated lineage $1-$ and lineage 2-infected mice in the main vaccine study were reduced to 8 each by day 1 PI. Characterization of the mouse pathology caused by the South African lineage 2 SPU93/01 WNV strain was one of the primary aims of the study, and hence the number of lineage 2-infected mice was increased by 5 sourced from the other study, which had used only the lineage 2 strain. In the in vivo animal studies, despite inbred laboratory strains of mice being relatively genetically homozygous and also specific pathogen free, there remains a degree of individual variation, manifested in the current trial as the differences in duration before individual mice showed clinical signs and in duration and severity of illness, leading to dissimilar numbers of mice dying on each of days 7 to 11 and 2 mice from each lineage infection group recovering. The highest number of mortalities occurred on day 9 PI (4 of lineage 2 and 2 of lineage 1). Previous reports of lineage $1 \mathrm{WNV}$ infection in experimental mice of other strains found the first clinical signs and deaths occurred on day 9 PI, ${ }^{14,21,36}$ with the most severe histological lesions and highest viral load in the CNS on days 9 and 10 PI. ${ }^{14,36}$ In these studies, as in the current study, the last deaths occurred on day $11 \mathrm{PI}$, and from day $13 \mathrm{PI}$, when they were considered survivors, viral load in the CNS diminished but CNS IHC labeling continued, with some inflammation in half the mice in 1 study up to day $21 \mathrm{PI}$, suggesting potential persistent infection. ${ }^{14}$ Similarly, a single lineage $2 \mathrm{WNV}$ survivor in the current study (case No. 23) was still rRT-PCR positive in the brain at day $21 \mathrm{PI}$.

Real-time RT-PCR and IHC negativity in day 5 PI euthanized mouse case Nos. 6 and 7 was expected due to low incubating virus titers prior to the onset of clinical signs. Similar negativity in case Nos. 14, 15 (lineage 1, day $8 \mathrm{PI}$ ), and 17 (lineage 2, day 9 PI) might have been due to individual variation with virus levels being too low for detection, unlikely minor differences in sample handling, or viral fluctuations (early clearance and later reintroduction) in the brain, as found in 4- to 6-week-old C57B1/6 lineage 1 (NY99) WNV-infected mice by Hunsperger et al. ${ }^{20}$ These mice in the current study were, however, initially infected with the same WNV dose via the same route, and all showed identical clinical signs and lesions to the other infected mice, which tested positive by one or other or both tests.

The variable locations of IHC WNV-positive neurons in this study, the paucity of light microscopically visible inflammatory changes or light microscopically visible pathology in virus- 

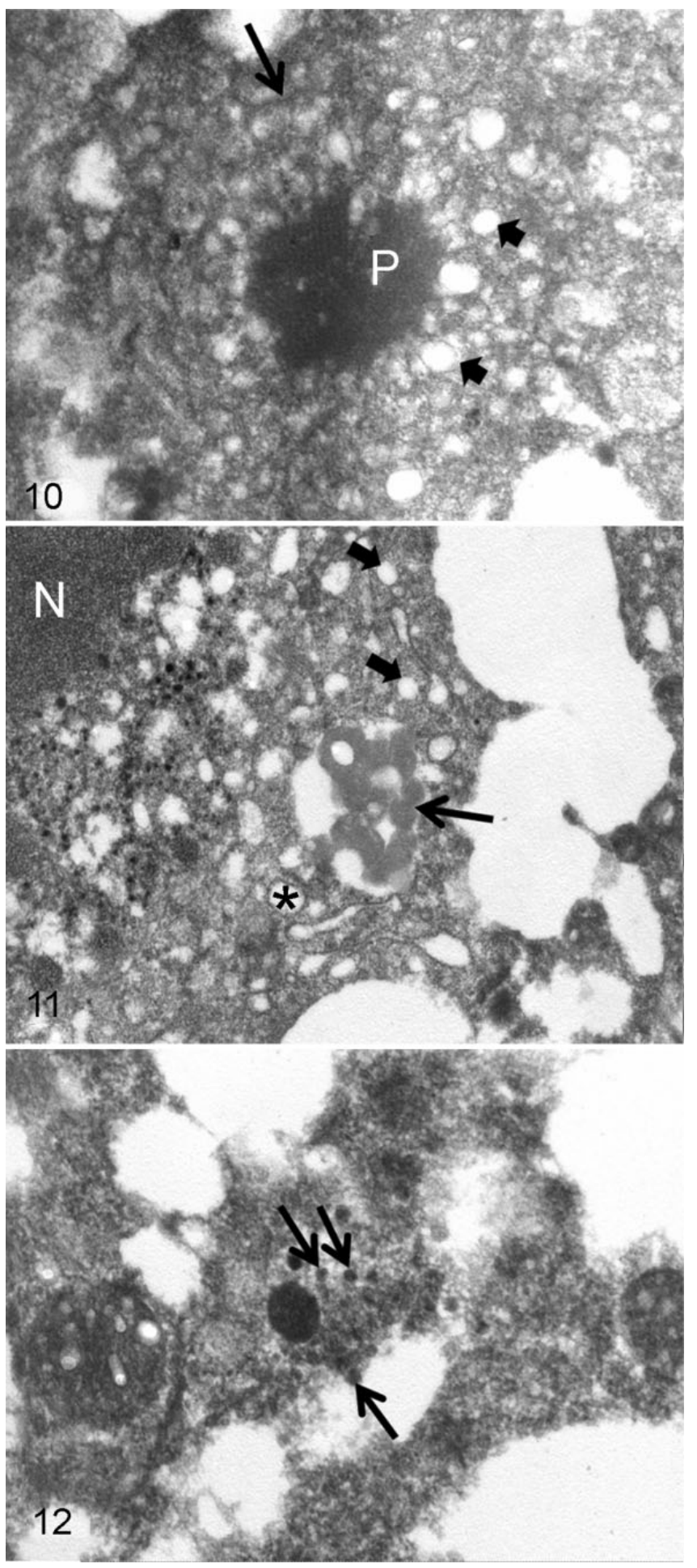

Figure 10. Avian cardiomyocyte; ultrastructure. Paracrystalline structure $(P)$ associated with vesicular structures (short arrows) and endoplasmic reticulum (long arrow). West Nile virus (WNV) E immunoperoxidase with Novored as chromogen and hematoxylin counterstain. Figure I I. Thalamic neuron ultrastructure; case No. I8, lineage 2 WNV, died day 9 postinfection (PI). Amorphous cytoplasmic inclusion (long arrow) associated with dilated endoplasmic reticulum (*) and vesicles (short arrows) in an immunohistochemistry (IHC)-positive area in the mouse neuron. Nucleus $(\mathrm{N})$. IHC-labeled histology positive cells, and lack of virus occurring perivascularly in association with lesions conflict with previous reports. $14,20,21,49,50$ The older mice used in this study, which were WNV infected 49 days after initial (at 7-8 weeks of age) and 21-day later booster mock vaccinations, as well as the BALBc strain not commonly used in WNV infection experiments, may have contributed to this difference in visible pathology from other reports. In general, younger mice $14,20,21,28$ and especially suckling mice $^{12}$ are most susceptible to WNV.

WNV is known to exert its influence by coding for inflammatory cytokines, ${ }^{14,24,49}$ and these may be sources of immunopathology, 2,24 as seen in species such as equines, which typically have very little or no IHC positivity in CNS neurons ${ }^{9,22,32}$ despite RT-PCR positivity and often prominent nonsuppurative encephalomyelitis. ${ }^{9,39}$ Despite extensive areas of brain being examined, in all mice dying or euthanized sick, CNS lesions were random, subtle, and without a particular pattern, unlike those in previous reports. ${ }^{21,29}$

Randomly scattered IHC positivity of neurons without light microscopical evidence of intracellular lesions or the presence of localized glial or leukocyte inflammatory response shares similarity with the finding by Hunsperger et $\mathrm{al}^{20}$ in dorsal root spinal ganglion neurons of lineage $1 \mathrm{WNV}$ footpad-inoculated mice that were IHC positive without cytopathic effect. Morrey et $\mathrm{al},{ }^{26}$ using hamsters as an experimental model for pathogenesis studies of WNV-induced flaccid paralysis, identified neuronal apoptosis and diminished cell function in the spinal cord by using terminal deoxynucleotidyl transferase-mediated BrdUTP nick end labeling (TUNEL) as well as choline acetyltransferase staining, respectively, where animals showed paralysis but no light microscopically visible neuronal lesions or inflammatory response. These labeling methods were not done but might have been enlightening in the current study.

Extra-CNS lesions found in the current study concurred in some macroscopic but not microscopic respects with findings by Kimura et $\mathrm{al}^{21}$ in lineage $1 \mathrm{WNV}$ footpad-inoculated 6-week-old $\mathrm{CH} 3$ mice. Gastric and small intestinal fluid distension were found in clinically affected mice in both studies. The shortened villi described in the Kimura et al study were found in only 2 mice in the current study: a healthy control mouse and a lineage 2 survivor. The widespread intestinal myenteric ganglion IHC positivity found in the Kimura et al study was not evident in the current study, with only 1 mouse showing unequivocal cecal ganglion labeling of neurons, which appeared normal and without the presence of leukocytes. Care was needed not to overinterpret myenteric ganglion changes, especially in the large intestine, in the current study due to varying degrees of autolysis in all mice that died and were not

Figure I I. (continued) section reembedded for transmission electron microscopy (TEM) and contrasted with uranyl acetate and lead citrate. Figure 12. Thalamic neuron; ultrastructure; case No. 18. Cluster of cytoplasmic virus-like particles (arrows) measuring approximately $50 \mathrm{~nm}$ in diameter in a non-IHC-positive cytoplasmic region. IHC-labeled histology section reembedded for TEM and contrasted with uranyl acetate and lead citrate. 
euthanized. The myenteric ganglia in all survivors appeared completely normal as they were in the noninfected controls, also suggesting that changes seen in the ganglia of clinically affected mice were more likely related to autolysis or were not significant.

Recent studies ${ }^{27,46}$ seeking to find neurological explanations for the respiratory, gastrointestinal, bladder, and cardiac dysfunction found in some humans with WNV infection used WNV-infected hamsters, which, like mice, ${ }^{21}$ show gastric and intestinal distension. They found by electromyograph (EMG) electrophysiological suppression of the diaphragm either directly due to WNV-infected neurons found by immunostaining in the brainstem and mid-cervical spinal cord or indirectly via altered vagal afferent function. ${ }^{27}$ Autonomic function and heart rate variability (HRV) were suppressed in the WNVinfected hamsters, leading to reduced HRV and EMG amplitudes of the gastrointestinal tract. ${ }^{46}$ In the current study, WNV IHC positivity was found in brainstem neurons in all 4 mice in which it was examined: 3 lineage 1 mice on days 7, 9, and 11 and 1 lineage 2 mouse on day 9 PI. These findings suggested a similar primarily CNS-origin etiology of gastric and intestinal stasis in the BALBc mice as was found in the hamsters. The pulmonary and surrounding lesions of case No. 22 were likely associated with distal esophageal perforation secondary to gastric distension and diaphragmatic paresis.

Intestinal lesions not previously recorded were found in mice infected with both lineages and were described and illustrated. Paneth cell degranulation was most likely in response to the presence of intraluminal bacterial overgrowth secondary to intestinal stasis. Paneth cell granules contain antimicrobial peptides and are functional in maintaining intestinal homeostasis. ${ }^{5}$ These cells in mice specifically contain $\alpha$-defensins as well as unique defense cryptdin-related sequences (CRS) peptides, which allow for a broad repertoire of potent microbicidal activity in the intestinal lumen. ${ }^{1}$

Similar to the findings in both lineage 1 and $2 \mathrm{WNV}$ infected mice of this study, lymphocyte or lymphoid depletion was previously recorded with lineage 1 infections of female 7- to 8-week-old C57BL/6 mice ${ }^{14,48}$ and 6-week-old C3H mice. ${ }^{21}$ Lesions in the current study were first seen histologically in the follicular marginal zone in 1 lineage 2 -infected mouse euthanized and examined at day $5 \mathrm{PI}$ in lymphoid tissue and also small intestine, prior to clinical signs of illness or rRT-PCR or IHC detectable virus, and progressed in both lineages from day 7 PI. The marginal zone of splenic germinal follicles contains dendritic macrophages important in the clearance of micro-organisms and viruses. ${ }^{10}$ WNV lineage 2 Sarafend strain infection of mice via any route was found to induce Tlr-3 from the cytoplasm of marginal zone splenocytes located near blood vessels: the production of inflammatory cytokines stimulated by Tlr-3 compromised the blood-brain barrier, allowing WNV entry into the CNS. ${ }^{49}$ Similar to the Kimura et $\mathrm{al}^{21}$ report, no clear IHC positivity was found in the spleen or other lymphoid tissue in the current study.

Hepatosis in some of the control, infected, and surviving mice may have been variably stress or disease related or due to a change in energy metabolism since sick mice were unable to eat. Pulmonary hemorrhages were interpreted as mostly traumatically induced during cardiac exsanguination.

Hayes et $\mathrm{al}^{19}$ stated that ultrastructural visualization of particles of WNV in WNV-infected tissues is rare, and when found, they are usually within the endoplasmic reticulum of neurons. EM findings in this study concurred with immunoelectron microscopy findings in the cerebrum and cerebellum from a WNV-infected Chilean flamingo studied by Steele et al. ${ }^{40}$ In that study, virions were much less intensely labeled than the presumed flaviviral-induced dense membrane vesicle structures and convoluted membranes, and these findings were consistent with immunoelectron microscopy of WNV-infected Vero cells. ${ }^{40}$ IHC-positive staining in the current study was therefore assumed to be of the ultrastructural preparticulate aggregates or of crystalline structures, suspected by Ghadially ${ }^{15}$ in 1988 to be viral. The paracrystalline amorphous or vesicular structures found in the IHC-positive control avian cardiomyocytes were similar to flavivirus-induced dense membrane vesicle structures described in Japanese encephalitis virus-infected cultured neurons. ${ }^{47}$ Steele et $\mathrm{al}^{40}$ also mentioned cytoplasmic vesiculation or vacuolation in association with flavivirus-induced structures. The amorphous structures found in the mouse neurons, although linked to endoplasmic reticulum and vesicles, differed from the paracrystalline structures in the avian cardiomyocytes.

\section{Conclusion}

Intraperitoneal inoculation of neurovirulent lineage 1 (NY99/ 385) or South African lineage 2 (SPU93/01) WNV strains in 3- to 4-month-old male BALBc mice caused similar clinical neurological disease and death with gross necropsy and histopathological lesions being indistinguishable between the lineages. CNS lesions were subtle despite severe neurological signs and may have indicated virus-associated biochemical damage with a paucity of light microscopically identifiable immunopathology in the older BALBc mice used. Gastrointestinal lesions were prominent and most likely initiated by stasis, which, based on IHC positivity of deep brainstem neurons, was suggestive as more likely of WNV-associated brainstem rather than local myenteric origin, although accurate interpretation of myenteric ganglion changes was hampered by autolytic changes and small intestinal distension. Ultrastructural findings of WNV-positive IHC-stained cells concurred with previous findings in WNV-infected birds that WNV particles are rare in WNV-infected tissues and not necessarily labeled with antibody and that other cytoplasmic structures that were labeled are most likely virus related.

\section{Acknowledgements}

The staff of the histopathology laboratory of the Pathology Section of the Faculty of Veterinary Science, University of Pretoria (UP) are thanked for the H\&E staining of sections and Mrs Marie Smit Rephima Phaswane for the immunohistochemical staining; the Paraclinical Department at UP for paying for the stains; Dr Josepha Delay 
of the Pathology Department of the University of Guelph, Ontario, Canada for the positive avian WNV lineage 1 tissue blocks as control; and Dr Louis Maartens of Deltamune and Dr Janusch Paweska of the NICD for allowing the experimental work to be done in their respective BSL3 laboratories. Professor John Lawrence and Andre Robinson are thanked for assistance with the manuscript and figure corrections, respectively.

\section{Declaration of Conflicting Interests}

The author(s) declared no potential conflicts of interest with respect to the research, authorship, and/or publication of this article.

\section{Funding}

The author(s) disclosed receipt of the following financial support for the research, authorship and/or publication of this article: The molecular biological tests and the infection experiments were funded by the National Research Foundation of South Africa or Pfizer Animal Health and the formalin bottles, histopathology, and immunohistochemistry by the Section of Pathology of the Department of Paraclinical Sciences of the Faculty of Veterinary Science, University of Pretoria, South Africa.

\section{References}

1. Andersson ML, Karlsson-Sjoberg JM, Putsep KL. CRS-peptides: unique defense peptides of mouse Paneth cells. Mucosal Immunol. 2012;5:367-376.

2. Bai F, Town T, Qian F, et al. IL-10 signaling blockade controls murine West Nile virus infection. PLoS Pathog. 2009;5: e1000610.

3. Bakonyi T, Ivanics E, Erdelyi K, et al. Lineage 1 and 2 strains of encephalitic West Nile virus, Central Europe. Emerg Infect Dis. 2006;12:618-623.

4. Beasley DWC, Li L, Suderman MT, et al. Mouse neuroinvasive phenotype of West Nile virus strains varies depending upon virus genotype. Virology. 2002;296:17-23.

5. Bevins C, Salzman NH. Paneth cells, antimicrobial peptides and maintenance of intestinal homeostasis. Nat Rev Microbiol. 2011;9:356-368.

6. Botha EM, Markotter W, Wolfaardt M, et al. Genetic determinants of virulence in pathogenic lineage 2 West Nile virus strains. Emerg Infect Dis. 2008;14:222-230.

7. Brown AN, Kent KA, Bennett CJ, et al. Tissue tropism and neuroinvasion of West Nile virus do not differ for two mouse strains with different survival rates. Virology. 2007;368:422-430.

8. Burt FT, Grobbelaar AA, Leman PA, et al. Phylogenetic relationships of Southern African West Nile virus isolates. Emerg Infect Dis. 2002;8:820-826.

9. Cantile C, Del Piero F, Di Guardo G, et al. Pathologic and immunohistochemical findings in naturally occurring West Nile virus infection in horses. Vet Pathol. 2001;38:414-421.

10. Cesta MF. Normal structure, function, and histology of the spleen. Toxicol Pathol. 2006;34:455-465.

11. Danis K, Baka A, Pangiotopoulos T, et al. ECDC Threat Assessment: Outbreak of West Nile Virus Infection in Greece, JulyAugust 2010. Stockholm, Sweden: European Centre for Disease Prevention and Control; 2010:1-6.
12. Eldadah AH, Nathanson N. Pathogenesis of West Nile virus encephalitis in mice and rats II: virus multiplication, evolution of immunofluorescence, and development of histological lesions in the brain. Am J Epidemiol. 1967;86:776-790.

13. Erdelyi K, Ursu K, Ferenczi E, et al. Clinical and pathologic features of lineage 2 West Nile virus infections in birds of prey in Hungary. Vector Borne Zoonotic Dis. 2007;7:181-188.

14. Garcia-Tapia D, Hassett DE, Mitchell WJJ, et al. West Nile virus encephalitis: sequential histopathological and immunological events in a murine model of infection. J Neurovirol. 2007;13: 130-138.

15. Ghadially FN. Ultrastructural Pathology of the Cell and Matrix. 3rd ed. London, UK: Butterworths; 1988.

16. Haines DM, Chelack BJ. Technical considerations for developing enzyme immunohistochemical staining procedures on formalinfixed paraffin-embedded tissues for diagnostic pathology. $J$ Vet Diagn Invest. 1991;3:101-112.

17. Hayat MA. Principles and Techniques of Electron Microscopy: Biological Applications. 4th ed. Cambridge, UK: Cambridge University Press; 2000.

18. Hayes EB, Gubler DJ. West Nile virus: epidemiology and clinical features of an emerging epidemic in the United States. Annu Rev Med. 2006;57:181-194.

19. Hayes EB, Sejvar JJ, Zaki SR, et al. Virology, pathology, and clinical manifestations of West Nile virus disease. Emerg Infect Dis. 2005;11:1174-1179.

20. Hunsperger EA, Roehrig JT. Temporal analyses of the neuropathogenesis of a West Nile virus infection in mice. J Neurovirol. 2006;12:129-139.

21. Kimura T, Sasaki M, Okumura M, et al. Flavivirus encephalitis: pathological aspects of mouse and other animal models. Vet Pathol. 2010;47:806-818.

22. Kleiboeker SB, Loiacono CM, Rottinhaus A, et al. Diagnosis of West Nile virus infection in horses. J Vet Diagn Invest. 2004;16: $2-10$.

23. Kutasi O, Bakonyi T, Lecollinet S, et al. Equine encephalomyelitis outbreak caused by a genetic lineage 2 West Nile virus in Hungary. J Vet Intern Med. 2011;25:586-591.

24. Lim SM, Koraka P, Osterhaus ADME, et al. West Nile virus: immunity and pathogenesis. Viruses. 2011;3:811-828.

25. MacKenzie JS, Gubler DJ, Petersen LR. Emerging flaviviruses: the spread and resurgence of Japanese encephalitis, West Nile and dengue viruses. Nat Med. 2004;10: S98-S109.

26. Morrey JD, Olsen AL, Siddharthan V, et al. Increased blood-brain barrier permeability is not a primary determinant for lethality of West Nile virus infection in rodents. J Gen Virol. 2008;89: 467-473.

27. Morrey JD, Siddharthan V, Wang H, et al. Neurological suppression of diaphragm electromyographs in hamsters infected with West Nile virus. J Neurovirol. 2010;16:318-329.

28. Nir Y, Beemer A, Goldwasser RA. West Nile virus infection in mice following exposure to a viral aerosol. Br J Exp Pathol. 1965;46:443-449.

29. Odelola HA, Oduye O. West Nile infection of adult mice by oral route. Arch Virol. 1977;54:251-253. 
30. Papa A, Bakonyi T, Xanthopoulou K, et al. Genetic characterisation of West Nile virus lineage 2, Greece, 2010. Emerg Infect Dis. 2011;17:920-922.

31. Papa A, Danis K, Baka A, et al. Ongoing outbreak of West Nile virus infections in humans in Greece, July-August 2010. Euro Surveillance. 2010;5:19644.

32. Pennick KE, McKnight CA, Patterson JS, et al. Diagnostic sensitivity and specificity of in situ hybridisation and immunohistochemistry for eastern equine encephalitis virus and West Nile virus in formalin-fixed, paraffin-embedded brain tissues of horses. J Vet Diagn Invest. 2012;24:333-337.

33. Petersen LR, Roehrig JT. West Nile virus: a reemerging global pathogen. Emerg Infect Dis. 2011;7:611-614.

34. Platonov AE, Fedorova MV, Karan LS, et al. Epidemiology of West Nile infection in Volgograd, Russia, in relation to climate change and mosquito (Diptera: Culicidae) bionomics. Parasitol Res. 2008;103:S45-S53.

35. Savini G, Capelli G, Monaco F, et al. Evidence of West Nile virus lineage 2 circulation in northern Italy. Vet Microbiol. 2012;158:267-273.

36. Shrestha B, Gottlieb D, Diamond MS. Infection and injury of neurons by West Nile encephalitis virus. J Virol. 2003;77:13203-13213.

37. Sirbu A, Ceianu CS, Panculescu-Gatej RI, et al. Outbreak of West Nile virus infection in humans, Romania, July to October 2010. Euro Surveillance. 2011;16:19762-19767.

38. Smithburn KC, Hughes TP, Burke AW, et al. A neurotropic virus isolated from the blood of a native of Uganda. Am J Trop Med. 1940;20:471-492.

39. Snook CS, Hyman SS, Del Piero F, et al. West Nile virus encephalomyelitis in eight horses. $J$ Am Vet Med Assoc. 2001;218: 1576-1579.

40. Steele K, Linn MJ, Schoepp RJ, et al. Pathology of fatal West Nile virus infections in native and exotic birds during the 1999 outbreak in New York City, New York. Vet Pathol. 2000;37:208-224.

41. Venter M, Burt FT, Leman PA, et al. Cytokine induction after laboratory-acquired West Nile virus infection. $N$ Engl J Med. 2009;360:1260-1262.
42. Venter M, Human S, Van Niekerk S, et al. Fatal neurologic disease and abortion in mare infected with lineage 1 West Nile virus, South Africa. Emerg Infect Dis. 2011;17:1534-1536.

43. Venter M, Human S, Zaayman D, et al. Lineage 2 West Nile virus as cause of fatal neurologic disease in horses, South Africa. Emerg Infect Dis. 2009;15:877-884.

44. Venter M, Jansen van Vuren P, Mentoor J, et al. Inactivated West Nile virus (WNV) vaccine, Duvaxyn WNV, protects against a highly neurovirulent lineage $2 \mathrm{WNV}$ strain in mice. Vaccine. 2013;31:3856-3862.

45. Venter M, Myers TG, Wilson AM, et al. Gene expression in mice infected with West Nile virus strains of different neurovirulence. Virology. 2005;342:119-140.

46. Wang H, Siddharthan V, Hall JO, et al. Autonomic nervous dysfunction in hamsters infected with West Nile virus. PLoS One. 2011;6:e19575.

47. Wang J-J, Liao C-L, Chiou Y-W, et al. Ultrastructure and localization of E proteins in cultures neuron cells infected with Japanese encephalitis virus. Virology. 1997;238:30-39.

48. Wang T, Fikrig E. Immunity to West Nile virus. Curr Opin Immunol. 2004;16:519-523.

49. Wang T, Town T, Alexopoulou L, et al. Toll-like receptor 3 mediates West Nile virus entry into the brain causing lethal encephalitis. Nat Med. 2004;10:1366-1373.

50. Wang Y, Lobigs M, Lee E, et al. CD8+ T cells mediate recovery and immunopathology in West Nile virus encepahlitis. $J$ Virol. 2003;77:13323-13334.

51. Wohlsein P, Deschl U, Baumgartner W. Nonlesions, unusual cell types, and postmortem artifacts in the central nervous system of domestic animals. Vet Pathol. 2013;50:122-143.

52. Zaayman D, Human S, Venter M. A highly sensitive method for the detection and genotyping of West Nile virus by real-time PCR. J Virol Methods. 2009;157:155-160.

53. Zaayman D, Venter M. West Nile virus neurological disease in humans, South Africa, September 2008-May 2009. Emerg Infect Dis. 2012;18:2051-2054. 